Bentham open Open Pharmaceutical Sciences Journal

RESEARCH ARTICLE

\title{
Improvement in Dissolution of Bosentan Monohydrate by Solid Dispersions Using Spray Drying Technique
}

\author{
Pankaj V. Dangre*, Vikesh B. Sormare and Mangesh D. Godbole \\ Department of Pharmaceutics, Kamla Nehru College of Pharmacy, Butibori, Nagpur-441108, Maharashtra, India
}

Received: January 10, 2017

Revised: February 20, 2017

Accepted: March 02, 2017

\begin{abstract}
:
Background:

Bosentan monohydrate (BM), a dual endothelin receptor antagonist, is indicated for the treatment of patients with pulmonary arterial hypertension (PAH). It is poorly soluble in water, and having absolute bioavailability of $50 \%$.
\end{abstract}

\section{Objective:}

The aim of the present work is to develop and evaluate the solid dispersions (SD) of a poorly water soluble drug bosentan monohydrate (BM).

\section{Method:}

Solid dispersions (SDs) systems of BM were prepared with Hydroxy propyle $\beta$-cyclodextrin (HP $\beta$-CD) and Polyethylene glycol (PEG-4000) polymers using a spray drying technique.

\section{Result:}

The significant rise in a saturation solubility $174.23 \pm 1.36 \mathrm{mg} / \mathrm{mL}$; and drug dissolution $95.11 \pm 1.22 \%$; was observed with optimized formulation (SD 6). The solid state characterization of optimized formulation (SD 6) by SEM, DSC, and XRPD revealed the absence of crystalline nature of BM in solid dispersion. High dissolution rate of solid dispersion (SD 6) compared with pure drug indicated the increase in dissolution characteristics.

\section{Conclusion:}

In conclusion, our studies illustrated that spray drying technique could be useful large scale producing method to prepare the solid dispersion of bosentan with HP $\beta-\mathrm{CD}$, which can improve the solubility as well as stability of the formulation.

Keywords: Bosentan monohydrate, Solid dispersion, Hydroxy propyle $\beta$-cyclodextrin, Polyethylene glycol, Spray drying.

\section{INTRODUCTION}

Oral route is always favored and widely accepted for the administration of drug and it is firstly investigated in the development of new dosage form. With the recent advent of high throughput screening and combinatorial chemistry methods, the number of new chemical entities (NCE) that possess pharmacological activity has risen sharply and thus candidates for pharmaceutical development. However, it has been estimated that the majority of all NCE entering in pharmaceutical development programs possess insufficient aqueous solubility to allow complete gastrointestinal absorption at a magnitude sufficient to ensure therapeutic efficacy [1, 2].

A number of alternative technologies are being developed to overcome the drawbacks associated with poor aqueous

\footnotetext{
* Address correspondence to this author at the Kamla Nehru College of Pharmacy, Butibori, Nagpur, Maharashtra, India; Tel:+91 9960160479; E-
} mail: pankaj_dangre@rediffmail.com 
solubility, for example, including use of surfactants [3], micronization [4], inclusion complexation [5] and solid dispersion [6]. Among these solid dispersion has gained importance as a promising approach, as the other methods suffer from limitation like size reduction by micronization, results in the formation of surface charge on particles which restrict their flow and exhibit poor flow properties [7]. Furthermore, drug solubilization from solid dispersion system is mainly due to particle size reduction, increased surface area, reduction in crystallinity and increased wettability by a surrounding hydrophilic carrier that improves the dissolution rate [8]. Among the solid dispersion techniques, spray drying offers numerous advantages over the other methods like; no drug and carrier decomposition (mostly occurred during fusion process in melting method) [9], no solvent limitation (as happened in case with solvent evaporation where the single organic solvent has solubility difference for drug and carrier employed for preparing solid dispersions) [10] and it is most suitable for large scale-up of products [11].

Bosentan monohydrate (BM), a dual endothelin receptor antagonist, is indicated for the treatment of patients with pulmonary arterial hypertension (PAH) [12]. It is poorly soluble in water, and having absolute bioavailability of $50 \%$ [13]. Therefore, improvement in solubility and/or dissolution rate of bosentan may be achieved through the formation of solid dispersion. Literature reported on the enhancement of solubility of bosentan monohydrate by using mixed hydrotropy approach [14].

In the present study, spray drying technique was utilized to prepare a solid dispersion of bosentan with hydroxy propyl $\beta$-cyclodextrin (HP $\beta$-CD) and polyethylene glycol 4000 (PEG 4000). Spray drying technique successfully employed for the improvement in dissolution of indomethacin [15], tolbutamide [16], carbamazepine [17], ketoprofen [18], and albendazol [19]. Solid dispersion in the form of spray dried powder was characterized by drug content, saturation solubility, dissolution rate, Scanning Electron Microscopy (SEM), Thermal analysis, Radiograph powder diffraction (XRPD) and Infrared spectroscopy (FT-IR).

\section{MATERIALS AND METHODS}

Bosentan monohydrate was provided by Cipla Pvt. Ltd. (Mumbai, India). Hydroxy propyl $\beta$ - cyclodextrin (HP $\beta$ CD) and polyethylene glycol (PEG 4000) was purchased from Loba Chem Ltd. (Mumbai, India). All chemicals and reagents used were of analytical grade.

\section{PREPARATION OF SOLID DISPERSION}

Bosentan was dissolved in methanol $(10 \% \mathrm{w} / \mathrm{v})$ along with each of the HP $\beta$-CD and PEG 4000 in different ratios $(1: 1,1: 3,1: 5)$ of drug carrier. Spray drying technique was employed to prepare solid dispersions since it allows rapid solvent evaporation leading to fast transformation of drug: carrier solution to solid drug: carrier particles. Furthermore, spray drying technology has wider application in commercial pharmaceutical industry because it is simple, rapid and economical. The solutions were mixed well to obtain a clear solution. The clear solutions were spray-dried using a spray dryer (Labultima, Mumbai, India) under fallowing set of parameters i.e. Inlet temperature $80^{\circ} \mathrm{C}$, outlet temperature $55^{\circ} \mathrm{C}$, feed pump rate $8 \mathrm{~mL} / \mathrm{min}$, aspiration rate $45 \mathrm{~m}$ bar, atomization air pressure $2.5 \mathrm{~kg} / \mathrm{cm}^{2}$. The resulting solid dispersions were subsequently desiccated under vacuum for $24 \mathrm{~h}$ to remove residual solvents. The dried mass then triturated and passed through sieve No. 80 to get uniformity in the size of the particles and were stored in tightly closed container until further use.

\section{EVALUATION OF PREPARED SOLID DISPERSION}

\subsection{Drug Content Determination}

The percentage of drug content in solid dispersions was estimated by dissolving the solid dispersions equivalent to $10 \mathrm{mg}$ of bosentan in $100 \mathrm{~mL}$ of methyl alcohol. Each of these solutions ware further diluted with phosphate buffer (pH 6.8) and absorbance were measured at $273 \mathrm{~nm}$.

\subsection{Saturation Solubility Studies}

To the glass vials containing $5 \mathrm{~mL}$ of phosphate buffer ( $\mathrm{pH}$ 6.8) excess quantity of pure drug and each solid dispersions were added separately. These vials were shaken at $20 \mathrm{rpm}$ for $24 \mathrm{~h}$ at temperature $37 \pm 0.5^{\circ} \mathrm{C}$ using orbital shaking cum incubator (Remi). The samples then filter through Whatman filter paper (No-41), appropriate dilutions were made with phosphate buffer ( $\mathrm{pH}$ 6.8) and analyzed spectrophotometrically by measuring absorbance at $273 \mathrm{~nm}$. 


\subsection{Drug Dissolution Studies}

Dissolution studies of Bosentan and its solid dispersions were performed using a USP XXII type II dissolution test apparatus (Electrolab-TDT 08L). The samples equivalent to $32 \mathrm{mg}$ of bosentan were placed in a dissolution vessels containing $900 \mathrm{~mL}$ of phosphate buffer $(\mathrm{pH} 6.8)$ maintained at $37 \pm 0.5^{\circ} \mathrm{C}$ and stirred at $100 \mathrm{rpm}$ [20]. The aliquots of 5 $\mathrm{mL}$ were removed at predetermined intervals of time and replaced immediately with the fresh dissolution medium. The samples were filtered and analyzed spectrophotometrically by measuring absorbance at $273 \mathrm{~nm}$.

\subsection{Fourier Transforms Infrared Spectroscopy Studies (FTIR)}

The FT-IR spectra of Bosentan, polymers and solid dispersions were obtained using FT-IR spectrometer having DRS attachment (84000s Shimadzu Corporation, Japan). About 2-3 mg of samples was mixed with dry $\mathrm{KBr}$ and the spectra scanned over wave number range of $4000-400 \mathrm{~cm}^{-1}$.

\subsection{Differential Scanning Calorimetric Analysis (DSC)}

Thermal behavior of pure drug, polymer and solid dispersion was studied by DSC (Mettle Star SW 10). The each sample was placed in aluminum crucible and heated at a rate of $10^{\circ} \mathrm{C} / \mathrm{min}$ in the range of $45^{\circ} \mathrm{C}$ to $250^{\circ} \mathrm{C}$. Inert atmosphere was provided by purging nitrogen gas at flow rate of $50 \mathrm{~mL} / \mathrm{min}$.

\subsection{X-Ray Powder Diffractometry (XRPD)}

$\mathrm{X}$-ray diffraction pattern of selected solid dispersion was compared with that of pure drug. This was done by measuring the $2 \theta$ in the range of $4-40^{\circ}$ with the reproducibility of \pm 0.001 on diffractometer (Brucker axs D8 Advance, Germany). The XRPD pattern was recorded automatically with the rate meter with the time constant of $2 \times 10^{2}$ pulse/second and with the scanning speed $20 / \mathrm{min}$.

\subsection{Scanning Electron Microscopy (SEM)}

SEM analysis of selected solid dispersion was carried out by scanning electron microscope (JSM 6360A Jeol Ltd, Tokyo, Japan). The sample was mounted on a double adhesive tape stuck to an aluminum stub coated with the platinum. The sample was scanned and photomicrograph was taken at an acceleration voltage of $10 \mathrm{kv}$.

\subsection{Stability Studies}

The stability study was carried out on selected formulation (SD 6). The selected formulation sealed in aluminum packaging coated inside with polyethylene and various replicates were kept in humidity chamber (Bio-Technics, Ltd, India) maintained at $40 \pm 2^{\circ} \mathrm{C} / 75 \pm 5 \% \mathrm{RH}$ for 3 months to assess its stability. After 45 and 90 days formulation was withdrawn and analyzed for physical appearance, drug content (\%) and cumulative drug release (\%).

\section{RESULT AND DISCUSSION}

The process conditions for spray drying were optimized accordance with the practical yield of dispersions.

\subsection{Drug Content Determination}

The percent yield of solid dispersion of bosentan with HP $\beta-C D$ and PEG 4000 was $67-70 \%$, and 59-62\% respectively. The spray dried dispersion was in the form of free flowing, hygroscopic, solid fine powder having 95.93 to 99.58\% drug content as presented in Table 1, showing uniform distribution of drug in solid dispersion and good flow and compressibility characteristics.

Table 1. Composition of solid dispersion and evaluation of drug content, saturation solubility and cumulative drug release.

\begin{tabular}{|c|c|c|c|c|c|}
\hline Sr. No & Batch code & Drug: Carrier & $\begin{array}{c}\text { Drug content } \\
(\mathbf{\%})\end{array}$ & $\begin{array}{c}\text { Saturation solubility } \\
\text { (mg/mL) }\end{array}$ & $\begin{array}{c}\text { Cumulative drug release (\%) } \\
\text { after 60 min }\end{array}$ \\
\hline 1 & Pure drug & -- & -- & $55.54 \pm 1.02$ & $37.70 \pm 2.22$ \\
\hline 2 & SD1 & $1: 1$ (PEG 4000) & $95.77 \pm 1.48$ & $88.72 \pm 1.63$ & $73.28 \pm 1.21$ \\
\hline 3 & SD2 & $1: 3$ (PEG 4000) & $96.16 \pm 1.11$ & $104.33 \pm 1.52$ & $78.59 \pm 1.23$ \\
\hline 4 & SD3 & $1: 5$ (PEG 4000) & $99.23 \pm 0.86$ & $123.63 \pm 1.73$ & $92.25 \pm 1.35$ \\
\hline 5 & SD4 & $1: 1$ (HPß-CD) & $95.39 \pm 0.78$ & $110.24 \pm 1.99$ & $82.75 \pm 1.45$ \\
\hline 6 & SD5 & $1: 3$ (HPß-CD) & $95.43 \pm 0.43$ & $138.16 \pm 1.69$ & $90.25 \pm 1.54$ \\
\hline
\end{tabular}




(Table () contd.....
\begin{tabular}{|c|c|c|c|c|c|}
\hline Sr. No & Batch code & Drug: Carrier & $\begin{array}{c}\text { Drug content } \\
(\mathbf{\%})\end{array}$ & $\begin{array}{c}\text { Saturation solubility } \\
(\mathbf{m g} / \mathbf{m L})\end{array}$ & $\begin{array}{c}\text { Cumulative drug release (\%) } \\
\text { after } \mathbf{6 0} \text { min }\end{array}$ \\
\hline 7 & SD6 & $1: 5(\mathrm{HP} \beta-\mathrm{CD})$ & $99.58 \pm 1.18$ & $174.23 \pm 1.36$ & $95.11 \pm 1.22$ \\
\hline
\end{tabular}

Data represented as percent mean $\pm \mathrm{SD}, \mathrm{n}=3 ; \mathrm{p}<0.01$

\subsection{Saturation Solubility Studies}

Fig. (1) shows significant improvement in saturation solubility of solid dispersion over pure drug. The increase in solubility 55.5 to $174 \%$ was observed when the drug was formulated into solid dispersion using carrier HP $\beta-C D$ in $1: 5$ ratio. The presence of carrier i.e. HP $\beta-C D$ and PEG 4000 in sample solution shows no interference in absorbance of drug.

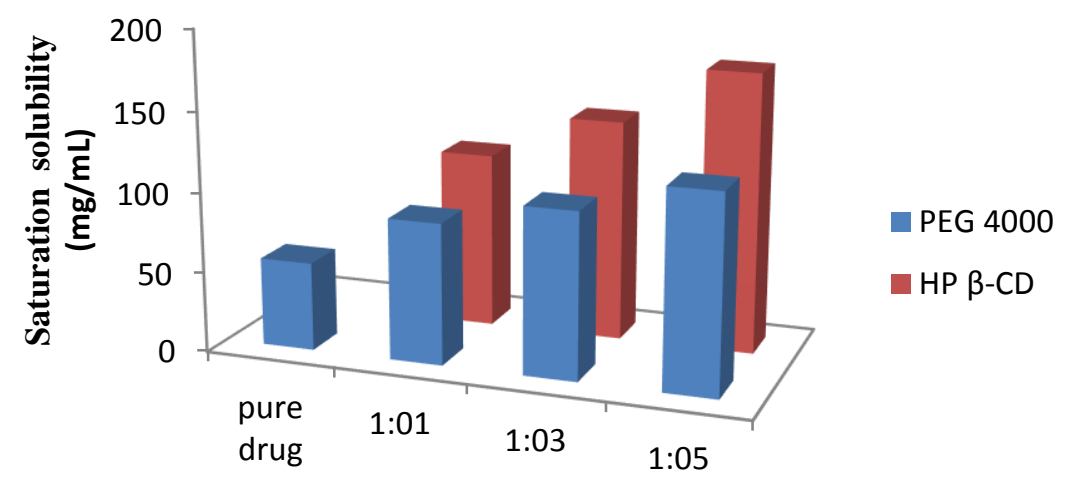

Fig. (1). Saturation solubility of solid dispersions.

\subsection{Drug Dissolution Studies}

An increased saturation solubility of drug leads to improvement in dissolution of drug as per the Noyes and Whitney equation (Figs. 2 and 3). This could be attributed to the decreased crystallinity of bosentan as revealed by DSC and XRPD studies, and reduction in particle size. The reduction in particle size during the spray drying, increases the surface area of particles and thus promoting higher dissolution rate. HP $\beta$-CD and PEG 4000 improve the wettability of drug particles and it acted on the diffusion layer surrounding the drug particles involving rapid inclusion of the solvent molecules thereby increasing the dissolution rate.

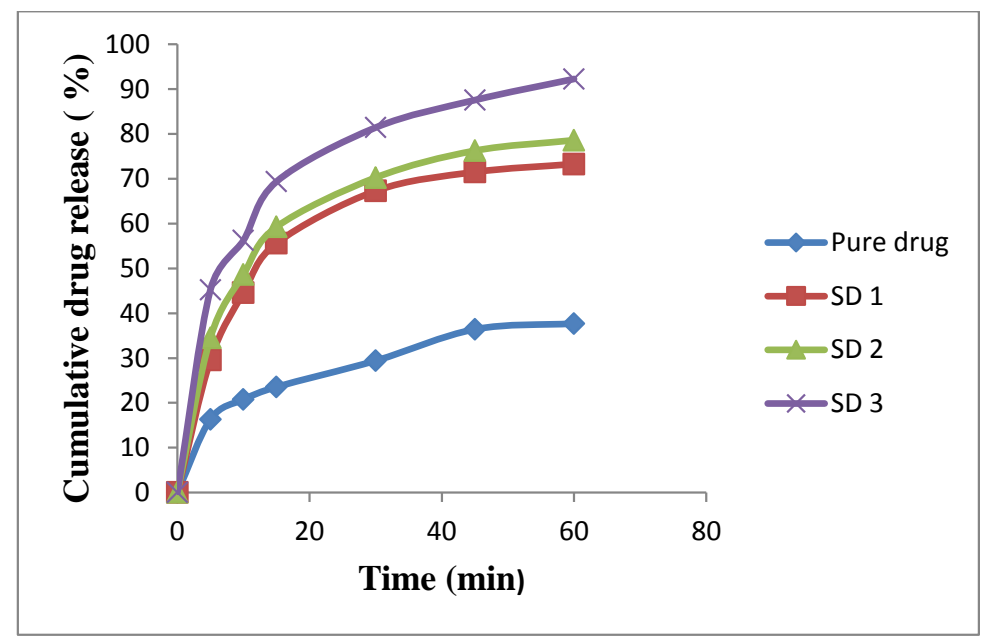

Fig. (2). Release rate profile of bosentan from solid dispersions prepared with PEG 4000 (Mean \pm SD; n=3). 


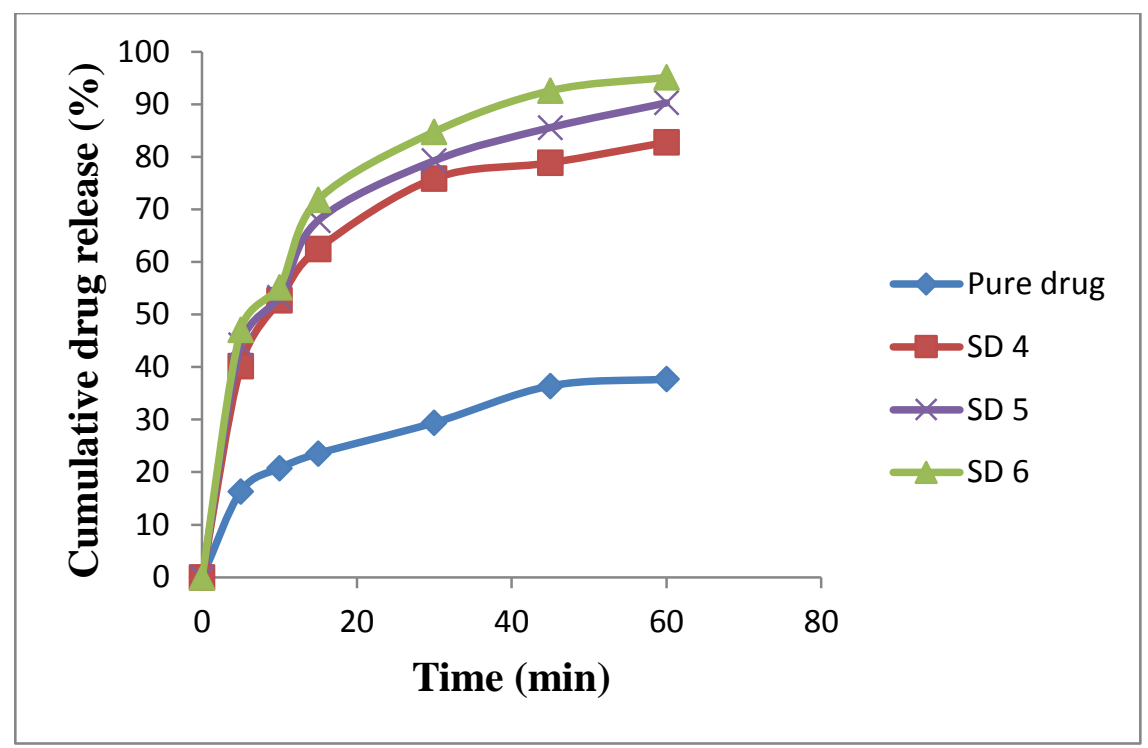

Fig. (3). Release rate profile of bosentan from solid dispersions prepared with HP $\beta-C D$ (Mean \pm SD; $n=3$ ).

Slightly better release profiles were observed for solid dispersion prepared with HP $\beta$-CD than PEG 4000; this could be possible because of inherent differences between two carriers in terms of hydration, possible complexation and degree of amorphization of carrier with drug. As the dissolution study progresses with time, increased in drug release was observed. At the end of $60 \mathrm{~min}, 95.11 \pm 1.22 \%$ drug was released from solid dispersion prepared using drug: $\mathrm{HP} \beta-\mathrm{CD}$ in the ratio 1:5 which was highest when compared with other solid dispersions.

\subsection{Fourier Transforms Infrared Spectroscopy Studies (FTIR)}

The FT-IR spectrum (Fig. 4) of Bosentan showed characteristics peaks at $2960.73 \mathrm{~cm}^{-1}\left(\mathrm{CH}_{3}\right.$ - stretching), 3493.09 $\mathrm{cm}^{-1}$ (OH- stretching), $1080.14 \mathrm{~cm}^{-1}$ (C-O stretching in ether) and $1384.89 \mathrm{~cm}^{-1}$ ( $\mathrm{S}=\mathrm{O}$ stretching). The FT-IR spectra of solid dispersion showed slight shift in lower wave number of stretching peaks $2927 \mathrm{~cm}^{-1}\left(\mathrm{CH}_{3}\right.$ - stretching), $3383 \mathrm{~cm}^{-1}$ (OH- stretching) with no difference in overall spectrum. This observation reveals possibility of intermolecular hydrogen bonding in the solid dispersion.
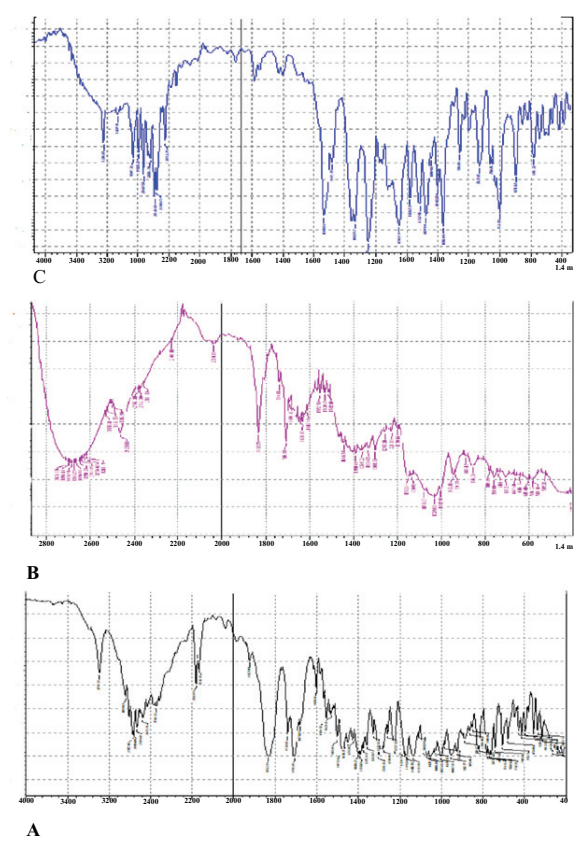

Fig. (4). Fourier-transform infrared (FTIR) spectroscopy spectra of bosentan (A), HP $\beta$-CD (B) and solid dispersion SD 6 (C). 


\subsection{Differential Scanning Calorimetric Analysis (DSC)}

The DSC curve of bosentan and its solid dispersion with HP $\beta-C D$ is shown in Fig. (5). The thermal curve of bosentan showed a sharp endothermic peak at $126.08^{\circ} \mathrm{C}$ corresponding to the melting point of drug. The sharp melting point of the drug indicates its crystalline characteristic. However, the DSC thermogram of solid dispersion (SD 6) showed a reduced and diffused endothermic peak. The diffused DSC pattern of solid dispersion (SD 6) revealed the shift in the endothermic peak and reduced intensity indicating the change in the crystalline nature of the drug. This transformation of the drug from crystalline nature to amorphous resulted in marked improvement in dissolution rate as the latter possess the high internal energy and considered as a state of high disorder.

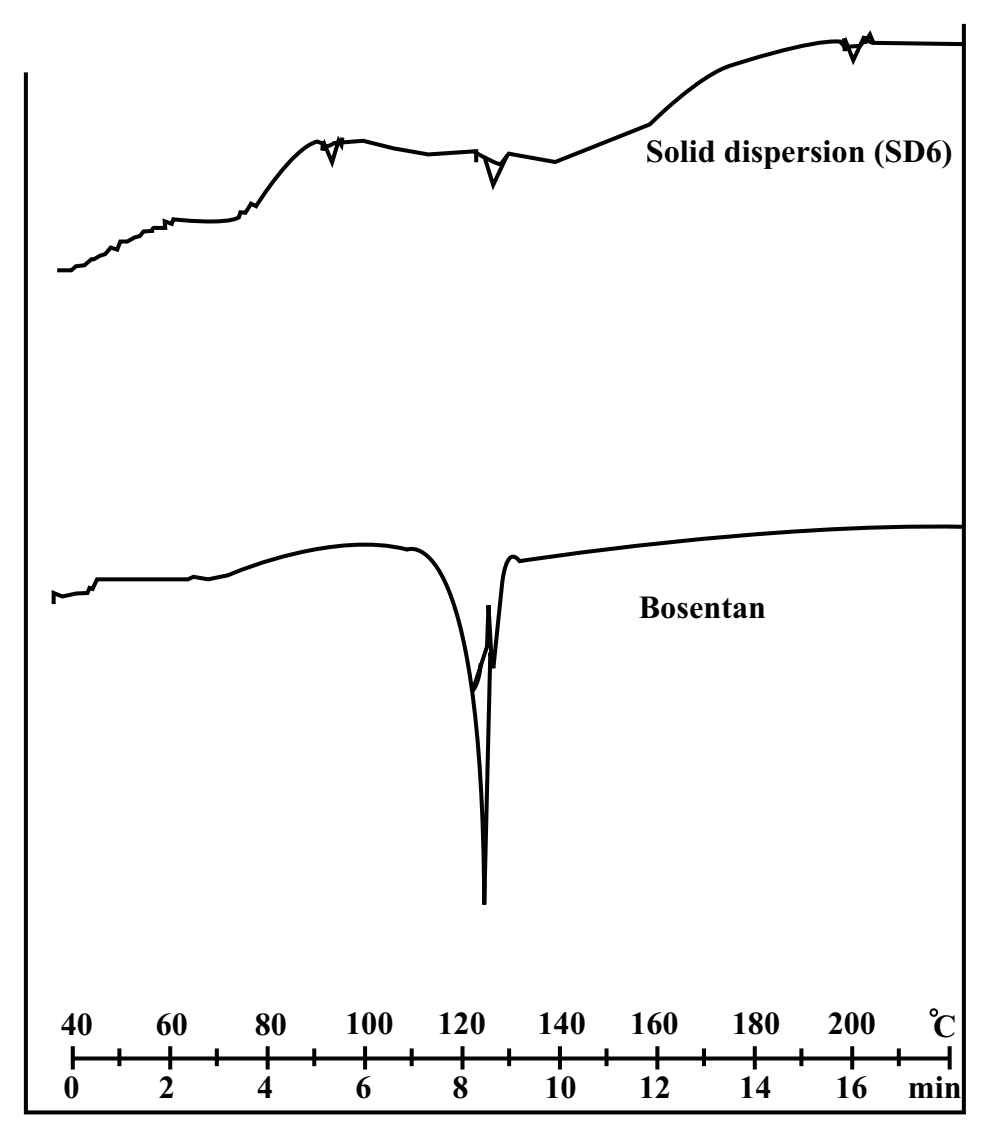

Fig. (5). Differential scanning calorimetry thermogram of pure drug and its solid dispersion with HPß-CD (SD 6).

\subsection{X-Ray Powder Diffractometry (XRPD)}

The XRPD pattern of drug, HP $\beta$-CD and its solid dispersion is shown in Fig. (6). The XRPD pattern of drug was characterized by the presence of sharp peaks at $21.8^{\circ}$ and $27.8^{\circ}$ indicating crystalline nature of drug. The sharpness of peaks as well as number of sharp peaks existing with plain drug was found to be significantly reduced in solid dispersion (SD 6) suggesting loss of crystalline nature of the drug. This transformation clearly indicated that the drug exists in molecularly dissolved state in solid dispersion which further governs the effective solubilization of the drug.

\subsection{Scanning Electron Microscopy (SEM)}

The scanning electron microscopy (SEM) photographs HP $\beta-C D$ and solid dispersion is shown in Fig. (7). HP $\beta$-CD is look like cup shape molecule with interior cavity. The interior of the cup is relatively a polar and creates hydrophobic microenvironment. HP $\beta$-CD therefore has exterior hydrophilic environment and interior hydrophobic cavity responsible for improving the aqueous solubility of poorly soluble drug. 


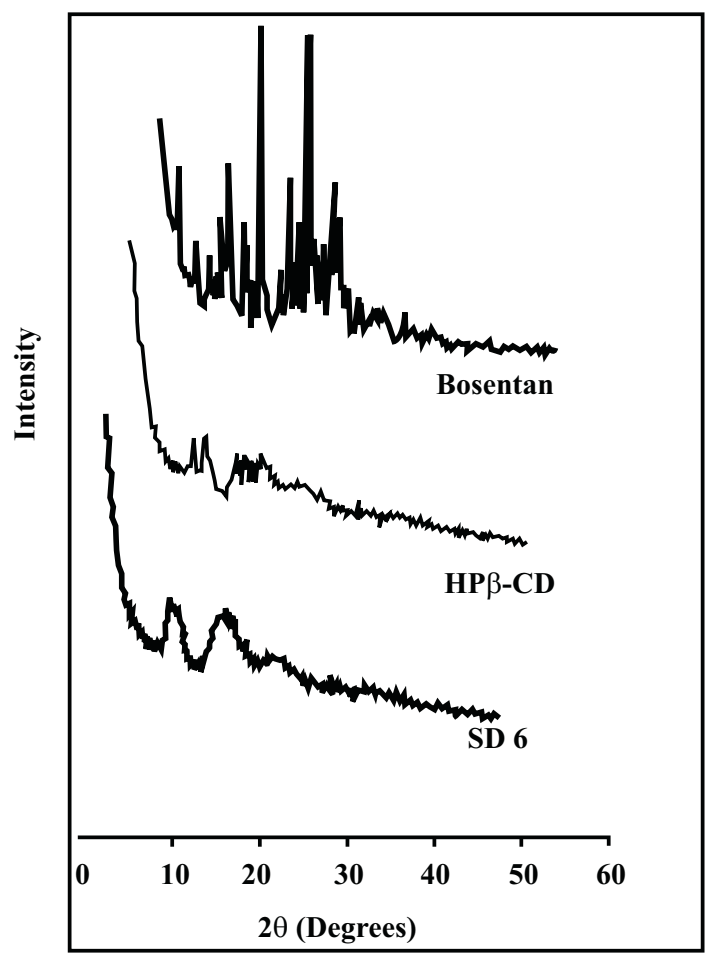

Fig. (6). X-ray powder diffraction spectra of Bosentan, HP $\beta$-CD and solid dispersion SD 6.

Table 2. Stability studies of optimized solid dispersion (SD 6) formulation at $40^{\circ} \mathrm{C} / 75 \% \mathrm{RH}$.

\begin{tabular}{|c|c|c|}
\hline & Initial & $\mathbf{4 5}$ days \\
\hline Physical appearance & $\begin{array}{c}\text { White color, } \\
\text { Free flowing powder }\end{array}$ & No change \\
\hline $\begin{array}{c}\text { Drug Content } \\
(\%)\end{array}$ & $99.58 \pm 1.18$ & $98.18 \pm 1.12$ \\
\hline $\begin{array}{c}\text { Cumulative drug release (\%) } \\
\text { After 60 min. }\end{array}$ & $95.11 \pm 1.05$ & $94.23 \pm 0.69$ \\
\hline
\end{tabular}

Data represented as percent mean $\pm S D, n=3 ; p<0.01$

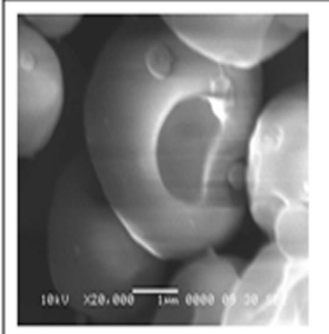

(A)

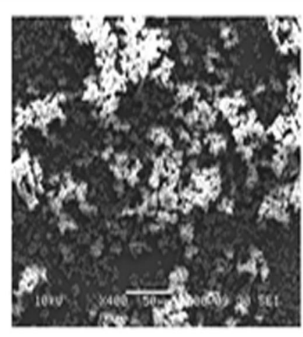

(B)

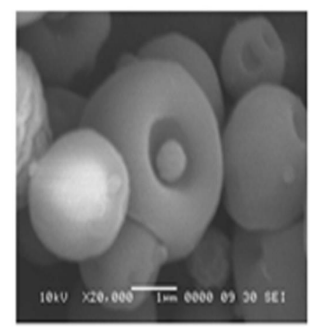

(C)

Fig. (7). Scanning electron microscopy photograph of HP $\beta$-CD (A), Inclusion complex of bosentan and HP $\beta$-CD in 1:5 ratio (B) and $(\mathbf{C})$. 
The SEM images of solid dispersion showed inclusion of drug within their cavities forming inclusion complex. The incorporation of drug molecule inside HP $\beta$-CD inclusion complex as a "guest" has been the basis for the improvement of solubility of drug.

\subsection{Stability Studies}

The stability studied was performed on selected solid dispersion formulation (SD 6). The formulation was stored at accelerated testing conditions for 3 months to assess its stability. The samples were withdrawn intermediately between 45 and 90 days of stability period and tested for physical appearance, drug content and percent cumulative drug release. On storage, stability of selected formulation (SD 6) showed no significant change as shown in Table 2. It is concluded that selected formulation was found to be stable over a period of three months.

\section{CONCLUSION}

The present investigation highlighted the simple and convenient method for preparation of solid dispersion of BM. The study proves that the solid dispersion of BM prepared using HP $\beta-C D$ and PEG 4000 has improved the dissolution rate of the drug significantly. However, better results were obtained with HP $\beta$-CD over the PEG 4000 and therefore considered for further evaluation. Physical studies showed the absence of chemical interactions between the drug and polymer. The nature and the concentration of the hydrophilic polymers have a critical role in the enhancement of the solubility. Solid dispersion (SD 6) was found to be superior in dissolution enhancement. This indicated that an increase in mass fraction of the polymer significantly improve dissolution rate. Based on these results, it can be concluded that solid oral dosage form of bosentan with HP $\beta$-CD could be formulated with a high dissolution rate, faster onset of action and can improved the bioavailability.

\section{CONFLICT OF INTEREST}

The authors confirm that this article content has no conflict of interest.

\section{ACKNOWLEDGEMENTS}

We are sincerely thankful to the secretary of Kamla Nehru College of Pharmacy, Butibori, Nagpur, India for providing the instrumental facility for carrying out the research work. We are also thankful to the Cipla Pvt. Ltd. Mumbai, India for providing the gift sample of Bosentan monohydrate.

\section{REFERENCES}

[1] Hauss DJ. Oral lipid-based formulations. Adv Drug Deliv Rev 2007; 59(7): 667-76. [http://dx.doi.org/10.1016/j.addr.2007.05.006] [PMID: 17618704]

[2] Benet LZ, Wu CY, Custodio JM. Predicting drug absorption and the effects of food on oral bioavailability. Bull Tech Gattefosse 2006; 99: 9-16.

[3] Duan RL, Sun X, Liu J, Gong T, Zhang ZR. Mixed micelles loaded with silybin-polyene phosphatidylcholine complex improve drug solubility. Acta Pharmacol Sin 2011; 32(1): 108-15. [http://dx.doi.org/10.1038/aps.2010.192] [PMID: 21170082]

[4] Huang QP, Wang JX, Chen GZ, Shen ZG, Chen JF, Yun J. Micronization of gemfibrozil by reactive precipitation process. Int J Pharm 2008; 360(1-2): 58-64.

[http://dx.doi.org/10.1016/j.ijpharm.2008.04.026] [PMID: 18502064]

[5] Wong JW, Yuen KH. Improved oral bioavailability of artemisinin through inclusion complexation with $\beta$ - and $\gamma$-cyclodextrins. Int J Pharm 2001; 227(1-2): 177-85.

[http://dx.doi.org/10.1016/S0378-5173(01)00796-7] [PMID: 11564552]

[6] Leuner C, Dressman J. Improving drug solubility for oral delivery using solid dispersions. Eur J Pharm Biopharm 2000; 50(1): 47-60. [http://dx.doi.org/10.1016/S0939-6411(00)00076-X] [PMID: 10840192]

[7] Boghra RJ, Kothawade PC, Belgamwar VS, Nerkar PP, Tekade AR, Surana SJ. Solubility, dissolution rate and bioavailability enhancement of Irbesartan by solid dispersion technique. Chem Pharm Bull (Tokyo) 2011; 59(4): 438-41. [http://dx.doi.org/10.1248/cpb.59.438] [PMID: 21467670]

[8] Craig DQ. The mechanisms of drug release from solid dispersions in water-soluble polymers. Int J Pharm 2002; $231(2)$ : $131-44$. [http://dx.doi.org/10.1016/S0378-5173(01)00891-2] [PMID: 11755266]

[9] Miller DA, McConville JT, Yang W, Williams RO III, McGinity JW. Hot-melt extrusion for enhanced delivery of drug particles. J Pharm Sci 2007; 96(2): 361-76. [http://dx.doi.org/10.1002/jps.20806] [PMID: 17075869] 
[10] Dontireddy R, Crean AM. A comparative study of spray-dried and freeze-dried hydrocortisone/polyvinyl pyrrolidone solid dispersions. Drug Dev Ind Pharm 2011; 37(10): 1141-9. [http://dx.doi.org/10.3109/03639045.2011.562213] [PMID: 21615280]

[11] Ambike AA, Mahadik KR, Paradkar A. Stability study of amorphous Valdecoxib. Int J Pharm 2004; $282(1-2)$ : 151-62. [http://dx.doi.org/10.1016/j.ijpharm.2004.06.009] [PMID: 15336390]

[12] Dingemanse J, van Giersbergen PL. Clinical pharmacology of bosentan, a dual endothelin receptor antagonist. Clin Pharmacokinet 2004; 43(15): 1089-115. [http://dx.doi.org/10.2165/00003088-200443150-00003] [PMID: 15568889]

[13] Divya M, Vani V, Rao U. Formulation and in-vitro evaluation of Bosentan Monohydrate microsphere. Pharmanest 2013; 4(6): $1539-57$.

[14] Saudagar RB, Shafi MM. Solubility enhancement of Bosentan Monohydrate using mixed hydrotropy. Int J Instit Pharm Life Sci 2015; 5(3): 319-30.

[15] Alanzi FK, El-Badry M, Ahmed MO, Alsarra IA. Spray dried HPMC microparticles of Indomethacin: impact of drug polymer ratio and viscosity of the polymeric solution on dissolution. Sci Pharm 2007; 75: 63-79.

[16] Chen R, Tagawa M, Hoshi N, Ogura T, Okamoto H, Danjo K. Improved dissolution of an insoluble drug using a 4-fluid nozzle spray-drying technique. Chem Pharm Bull (Tokyo) 2004; 52(9): 1066-70. [http://dx.doi.org/10.1248/cpb.52.1066] [PMID: 15340191]

[17] Filipović-Grcić J, Perissutti B, Moneghini M, Voinovich D, Martinac A, Jalsenjak I. Spray-dried carbamazepine-loaded chitosan and HPMC microspheres: preparation and characterisation. J Pharm Pharmacol 2003; 55(7): 921-31. [http://dx.doi.org/10.1211/0022357021503] [PMID: 12906749]

[18] Moretti MD, Gavini E, Juliano C, Pirisino G, Giunchedi P. Spray-dried microspheres containing ketoprofen formulated into capsules and tablets. J Microencapsul 2001; 18(1): 111-21. [http://dx.doi.org/10.1080/026520401750038647] [PMID: 11201334]

[19] Alanzi FK, El-Badry, Alsarra IA. Improvement of Albendazole dissolution by preparing microparticles using spray drying technique. Saudi J Pharm 2006; 14: 100-7.

[20] Kulthe VV, Chaudhari PD. Solubility enhancement of Etoricoxib by solid dispersions prepared by spray drying technique. Indian J Pharm Educ Res 2011; 45(3): 248-58.

(C) 2017 V. Dangre et al.

This is an open access article distributed under the terms of the Creative Commons Attribution 4.0 International Public License (CC-BY 4.0), a copy of which is available at: https://creativecommons.org/licenses/by/4.0/legalcode. This license permits unrestricted use, distribution, and reproduction in any medium, provided the original author and source are credited. 